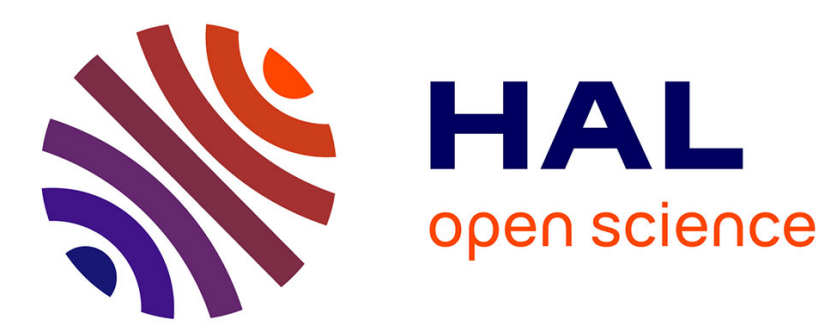

\title{
ELECTROHYDRODYNAMIC INSTABILITY IN A SUPERTHICK SUPERFLUID FILM
}

\author{
M. Cole, D. Goodstein, D. Kwoh
}

\section{To cite this version:}

M. Cole, D. Goodstein, D. Kwoh. ELECTROHYDRODYNAMIC INSTABILITY IN A SUPERTHICK SUPERFLUID FILM. Journal de Physique Colloques, 1978, 39 (C6), pp.C6-318-C6-320. 10.1051/jphyscol:19786141 . jpa-00217548

\section{HAL Id: jpa-00217548 https://hal.science/jpa-00217548}

Submitted on 1 Jan 1978

HAL is a multi-disciplinary open access archive for the deposit and dissemination of scientific research documents, whether they are published or not. The documents may come from teaching and research institutions in France or abroad, or from public or private research centers.
L'archive ouverte pluridisciplinaire HAL, est destinée au dépôt et à la diffusion de documents scientifiques de niveau recherche, publiés ou non, émanant des établissements d'enseignement et de recherche français ou étrangers, des laboratoires publics ou privés. 


\title{
ELECTROHYDRODYNAMIC INSTABILITY IN A SUPERTHICK SUPERFLUID FILM
}

\author{
M.W. Cole, D.L. Goodstein ${ }^{\dagger}$ and D. Kwoht \\ Pennsylvania State University, U.S.A. \\ + Califomia Institute of Technology, U.S.A.
}

Résumé.- Dans une expérience conçue pour l'êtude du potentiel d'un film d'hêlium très épais sous l'influence combinée des forces de van der Waals, de la gravité, et d'un champ êlectrique appliqué, nous avons découvert une instabilité électrohydrodynamique qui impose une limite sur 1 'épaisseur du film qui peut être atteinte par cette technique. La thêorie de l'instabilité et son observation sont. décrites.

Abstract.- In an experiment designed to study the potential of a very thick helium film under the combined influence of van der Waals forces, gravity, and an applied electric field, we have discovered and electrohydrodynamic instability which places an upper limit on the film thickness that can be reached by this technique. The theory of the instability and its observation are described.

When the interface of a dielectric liquid is subjected to a strong perpendicular electric field, an instability can occur owing to the opposing effects of gravitational and electric forces $/ 1 /$. The wavelength of the mode that becomes unstable is determined by the surface tension of the liquid. A related instability can occur in a superfluid film. In this case the instability condition is modified by the van der Waals force from the substrate, and boundary conditions imposed on the flow at the substrate. We describe briefly the theory of the instability, and an experimental ohservation of it.

A horizontal parallel plate capacitor of gap width $w$ is located with its lower plate a distance $h$ above the helium bath. In equilibrium there is a film on the lower plate whose thickness D is governed by

$\frac{-(\varepsilon-1)}{8 \pi \varepsilon} E_{v}^{2}-\frac{\rho}{m} v+\rho g_{0}(h+D)=0$

where $\varepsilon$ is the helium dielectric constant, $\mathrm{E}_{\mathrm{v}}$ the applied electric field, $\rho$ the liquid density (we take the superfluid fraction, $\rho_{s} / \rho=1$ at low temperature) and $g_{0}$ the acceleration of gravity. $\mathrm{V}=\mathrm{V}(\mathrm{D})$ is the van der Waals potential at the interface, and $m$ is the mass of a helium atom. A similar equation governs the thickness of the film on the upper capacitor plate. Equation (1) is obtained by setting the chemical potential at the bath interface equal to that at the film interface and imposing the condition that the normal component of Maxwel1 stress tensor, $\underset{\approx}{\sigma}$. n , be continuous at the interface $/ 2 /$.

To test for stability we consider a wave such that the departure of the interface from its equilibrium plane, $z=0$ is given by $\eta=\eta_{0}$ sin $k x$. This produces perturbations in the electric potential which must vanish at the upper and lower capacitor plates, and also maintain a continuous tangential $\underset{\sim}{\mathrm{E}}$ field and normal $D$ field at the interface. Terms of $o\left(n_{0}^{2}\right)$ are discarded. The equations of motion are

$\rho \frac{\partial \underline{v}}{\partial t}=\underset{\approx}{\sigma}+\rho g \hat{z}$

where $\underset{\sim}{v}$ is the (super) fluid velocity and

$g= \pm g_{0}-\frac{1}{m} \frac{d V}{d D}$

where + and - refer to the lower and upper film respectively. The boundary conditions are that the normal component of $\mathrm{v}$ must vanish at the capacitor plate, and

$\left(\sigma^{-}-\sigma\right) \cdot \hat{\mathrm{n}}=\alpha \nabla^{2} n$

where $\alpha$ is the liquid surface tension, and $\sigma^{\circ}$ is the stress tensor on the vapor side of the interface. Incompressible inviscid flow of small amplitude is assumed throughout.

Setting $n_{0}$ and the velocity potential proportional to $e^{-i \omega t}$, we find the dispersion relation

$$
\begin{aligned}
\omega^{2} & =\left[g k+\frac{\alpha}{\rho} k^{3}-\right. \\
& \left.-\frac{(\varepsilon-1)^{2}}{4 \pi \varepsilon \rho} \frac{k^{2} E_{v}^{2}}{(\tanh k D+\varepsilon \tanh k w)}\right] \tanh k D(5)
\end{aligned}
$$


where we have assumed $\mathrm{w} \gg D$.

Equation (5) has a number of familiar limiting cases, including Rayleigh surface waves, shallow water waves, the Taylor "dripping" instability, the bulk electrohydrodynamic instability referred to above, and in the helium film case, third sound. Searching for the thinnest film to go unstable, we find it occurs in the long wavelength limit, $k D \ll k w \ll 1$. In that case we find $\omega^{2}=0$ at a critical value of $\mathrm{E}_{\mathrm{v}}$ given by

$\frac{(\varepsilon-1)^{2}}{4 \pi \varepsilon^{2} \rho \mathrm{w}} \mathrm{E}_{\mathrm{v}}^{2}= \pm \mathrm{g}_{\mathrm{o}}-\frac{1}{\mathrm{~m}} \frac{\mathrm{dV}}{\mathrm{dD}}$

Together with equation (1), this gives a critical film thickness, $D_{c}$, at which instability occurs for any given $h$. To take an example relevant below, for $\mathrm{h}=0.15 \mathrm{~cm}$, assuming the expected $\mathrm{V}(\mathrm{D})$ for a meta1lic substrate $/ 3 /$ the film becomes unstable when $\mathrm{D}_{\mathrm{c}}{ }^{(l)}=5000 \AA$ (on the lower plate) or $\mathrm{D}_{\mathrm{c}}^{(\mathrm{u})} \simeq 4000 \AA$ on the upper plate.

The experiment is performed using a horizontal, circular, parallel plate capacitor of mean gap width $\overline{\mathrm{w}}=37.5 \mu \mathrm{m}$ and radius $0.236 \mathrm{~cm}$. A bath level is established approximately $0.15 \mathrm{~cm}$ below the lower plate, and the film thickness inside the capacitor is then varied by applying a dc electric field, and measured using a small ac field. The measurements are made at $T=0.5 \mathrm{~K}$, which minimizes vapor and two fluid effects. Considerable attention is given to assuring that the lower plate is horizontal, to surface preparation, and to vibration isolation. Details will be presented elsewhere.

Under the conditions described, the (absolutely) stable state of the system is with the capacitor gap filled owing to the effect of capillarity. Filling of the gap is irreversible. Once it occurs, the gap can be emptied again only by pumping away all of the helium in the experimental cell. The system is, however, metastable against filling the gap so long as the upper and lower film interfaces do not touch each other. This is the regime in which all measurements are made.

For a given outer bath leve1, a succession of measurements are made in which the dc electric field is increase and the film reaches a stable thickness which is recorded. Beyond a certain value of the field, it is found that any further increase causes the film to "run away", the thickness increasing continuously with time. If left in this condition, the gap fills. If the electric field is reduced before the upper and lower surfaces touch, however, the film rapidly returns to its previous stable thickness. It is this reversibility that shows that we are not observing the capillary instability that occurs when the upper and lower films touch.

A more quantitative test is hampered by the fact that the two predicted critical fields, that for the electrohydrodynamic instability and that for the capillary instability are too nearly equal to distinguish experimentally (error in measuring the gap width, $w$, introduces the uncertainty in $E_{v}$ ). We have evaded this difficulty by making a series of observations in a capacitor in which the upper plate is tilted by a smal1, known amount relative to the horizontal lower plate. The effect is to localize the position where the instability occurs (it occurs on the lower plate, where the gap is narrowest, and the field therefore strongest). Since the onset condition is now not subject to uncontrolled errors in horizontality, etc., it is possible to predict the mean (measured) film thickness when the thickest part of the lower film goes unstable. In particular, with a maximum change in gap width, $\delta w / w \simeq 0.05$ from the center of the p1ate to the outside, we predict from Lifshitz theory /3/ that when the film thickness reaches the critical value of about $5000 \AA$ on one side of the lower plate; the mean film thickness (upper and lower together) will be a little more than $1000 \AA$. The values vary slightly with $h$. In a series of 8 runs, the last stable average $\mathrm{film}$ thickness ranged from $880 \AA$ to $1040 \AA$ in excellent agreement with the prediction. This observation together with the reversible character of the instability cause is to believe that we have observed the electrohydrodynamic instability. 
11/ Kuznetsov, E.A. and Spektor, M.D., Zh. Eksp.Teor.Fiz. 71 (1976) 262 (English translation, Sov. Phys. JETP 44 (1976) 136) and references therein; Taylor, G.I. and McEwan, A.D., J. Fluid Mech. XXII (1965) 1

12/ Landau, L.D. and Lifshitz, E.M., Electrodynamics of Continuous Media (Addison-Wesley, Reading, Mass.) 1960, pp. 64-69

13/ Lifshitz, E.M., Zh. Eksp. Teor. Fiz. 29 (1955) 94 (English translation, Sov. Phys. JETP 2 (1956) 73). The potential has been computed numerically, assuming a substrate plasma frequency of $10 \mathrm{eV} / \mathrm{h}$. The actual capacitor surface is nickel. 